\title{
Desenvolvimento e aplicação de práticas desplugadas para o ensino de Redes de Computadores
}

\author{
Alejandro Cancela Melgaço ${ }^{1}$, Josualdo Dias ${ }^{1}$ \\ ${ }^{1}$ Instituto Federal de Educação, Ciência e Tecnologia da Bahia campus Porto Seguro - \\ Rod br 367, R. José Fontana, 1, Porto Seguro - BA, 45810-000. \\ alejandropsifba@gmail.com, josualdodiaseifba.edu.br
}

\begin{abstract}
This paper presents an experience report about a participant research in which Unplugged Computing was used as a strategy for the playful and meaningful teaching of Computer Networks. For this, unplugged learning objects were elaborated, and these were applied to the students enrolled in the Informatics Technician (TI) course of the Federal Institute of Education, Science and Technology of Bahia campus Porto Seguro. Based on an interpretative analysis, it was evidenced that unplugged learning objects promote the playful and meaningful teaching of Computer Networks.
\end{abstract}

Resumo. Este artigo apresenta um relato de experiência sobre uma pesquisa participante em que a Computação Desplugada foi utilizada como estratégia para o ensino lúdico e significativo de Redes de Computadores. Para isto, foram elaborados objetos de aprendizagem desplugados, e esses foram aplicados junto aos discentes matriculados no curso Técnico em Informática (TI) do Instituto Federal de Educação, Ciência e Tecnologia da Bahia campus Porto Seguro. Com base em uma análise interpretativa, foi evidenciado que os objetos de aprendizagem desplugados promovem o ensino lúdico e significativo de Redes de Computadores.

\section{Introdução}

O primeiro contato com a Computação Desplugada ocorreu em um componente curricular do curso de Licenciatura em Computação, nesse componente refletimos sobre as dificuldades no processo de ensino e aprendizagem dos conceitos da Ciência da Computação. Além de refletir sobre essas dificuldades, buscamos alternativas didáticas que pudessem contribuir para o ensino mais eficiente dos conceitos da Computação. Foi então que, pesquisando em monografias, artigos, revistas, vídeos, entre outros, descobrese a abordagem desplugada.

Após realizar mais pesquisas sobre a Computação Desplugada, compreendemos que se trata de uma estratégia apoiada pelo movimento Construtivista, e que visa ensinar Ciência da Computação sem utilizar aparatos tecnológicos em sala de aula. Ora, então como são ensinados os conceitos da Computação utilizando a Computação desplugada? Com a ludicidade manifestada através dos jogos, dança, teatro, música, etc. Através dessas formas lúdicas de abordar os conceitos, os alunos "desenvolvem ativamente habilidades de comunicação, resolução de problemas, criatividade, e cognição num contexto significativo" [Bell et al. 2011, p. 2].

Inquieto com a forma de ensino tradicional de Redes de Computadores, observouse na abordagem desplugada a oportunidade de contribuir para um processo de ensino e aprendizagem de Redes de Computadores mais lúdico e significativo. Segundo Cantú et 
VIII Congresso Brasileiro de Informática na Educação (CBIE 2019)

Anais do XXV Workshop de Informática na Escola (WIE 2019)

al. (2005) nessa forma tradicional de ensinar Redes, o professor é responsável por transmitir os seus conhecimentos aos discentes, e esses são agentes passivos nesse processo. Além disso, é desconsiderado os ritmos de aprendizagem dos alunos, e a motivação desses em estudar fica à mercê da obrigatoriedade em entregar trabalhos e realizar provas, acrescenta-se que os discentes ainda são penalizados pelos seus erros durante esse processo.

Cantú e Farines (2002) indagam sobre a influência dos livros na didática do professor, eles ainda relatam que esses livros são técnicos e não apresentam exemplos contextualizados com a vida do aluno. Cantú et al. (2005) reforça que essa forma tradicional de ensino de conceitos de Redes é majoritariamente adotada em sala de aula, mas parece não ser a estratégia mais adequada, de modo que, Redes de Computadores é caracterizada pela dinamização e inovação, bem como sua influência nas práticas da sociedade.

Nesse cenário, buscou-se responder se a Computação Desplugada pode ser utilizada como estratégia para o ensino lúdico e significativo de Redes de Computadores. Para tal, objetos desplugados foram construídos, aplicados e analisados. A pesquisa foi aplicada junto aos discentes do curso Técnico em Informática (TI) do Instituto Federal de Educação, Ciência e Tecnologia da Bahia campus Porto Seguro. Dessarte, o presente trabalho apresenta os resultados obtidos com a utilização da abordagem desplugada em Redes de Computadores.

O artigo está estruturado da seguinte maneira. Na seção 2 é apresentado o que é Computação Desplugada, em suas demais seções, respectivamente, é exposto trabalhos que utilizaram essa abordagem, e seu alicerce pedagógico. A seção 3 discorre sobre a metodologia científica utilizada no presente trabalho. Na seção 4 é mostrado os objetos de aprendizagem desplugados elaborados. A seção 5 explana os resultados e discussões obtidos com essa pesquisa. Por fim, a seção 6 relata as considerações finais do investigador.

\section{Computação Desplugada}

Segundo Bell et al. (2011) a Computação Desplugada é uma estratégia apoiada pelo movimento Construtivista, que busca ensinar conceitos da Ciência da Computação sem usar hardware ou software no ambiente de aprendizado. Essa estratégia foi elaborada por Tim Bell, Ian H. Witten e Mike Fellows. Esses pesquisadores escreveram um livro contendo diversas práticas desplugadas para serem aplicadas na sala de aula ou ao ar livre.

Nessas atividades desplugadas os alunos irão aprender os conceitos da Computação de forma lúdica, e vão descobrir por conta própria os padrões e ideias relacionados aos conhecimentos que são abordados nessas práticas [Cs Unplugged, 2019]. Outra vantagem que a Computação Desplugada oferece indagada por Bell et al. (2011), é a possibilidade dos objetos desplugados serem levados para lugares menos favorecidos, possibilitando que esses lugares tenham acesso ao conhecimento da Computação.

\subsection{Aprendizagem significativa com atividades desplugadas}

No estudo de Vieira, Passos e Barreto (2013) foram aplicadas peças teatrais para abordar os conceitos da Computação. As peças foram aplicadas junto aos discentes do ensino médio e fundamental de escolas públicas. Esses autores concluíram por meio de uma 
VIII Congresso Brasileiro de Informática na Educação (CBIE 2019)

Anais do XXV Workshop de Informática na Escola (WIE 2019)

avaliação qualitativa que os alunos compreenderam os conceitos que foram abordados através das peças, e que foi despertado nos discentes a intenção em estudar Ciência da Computação. Segundo Dohme (2003) as peças teatrais são de suma importância para o discente, de jeito que, possibilita a construção da autoestima, além disso, as apresentações constantes contribuem para o aluno vencer a timidez, assim, eles não terão dificuldades quando for preciso enfrentar públicos maiores, que possivelmente irá acontecer em suas vidas profissionais.

No estudo de Ferreira et al. (2015) a abordagem desplugada foi usada de maneira interdisciplinar. A intervenção foi feita em uma escola periférica de Salvador, com alunos do ensino médio. Foram aplicadas seis atividades desplugadas, contemplando matérias como Educação Física, Química, Artes, Biologia e Matemática. Ferreira et al. (2015) utilizou a dança em uma aula de Artes para abordar ordenação BubbleSort, QuickSort e SelectSort. Além desta, os alunos receberam um desafio na aula de Química e Biologia, sobre Equilíbrio Ecológico e Equilíbrio Químico, no fim, os discentes tiveram que escrever um algoritmo para resolver o desafio que foi proposto. Os estudiosos ainda abordaram a tabela verdade na aula de Educação Física, para isso, utilizaram papéis coloridos e garrafas PET, esses materiais também foram usados para abordar os conceitos relacionados a unidade de medida na aula de Matemática.

No trabalho de Gonçalves et al. (2013), foi desenvolvido o "EvOU”, um jogo para ensinar a Tabela Verdade. Esse jogo foi aplicado juntamente aos alunos matriculados no $1^{\mathrm{o}}$ e $3^{\circ}$ períodos do curso de Licenciatura em Computação do Instituto Federal de Minas Gerais - Ouro Branco. [Gonçalves et al. 2013, p. 343] destaca que, "é de suma importância que se façam trabalhos como esse, pois, incentivam o uso da criatividade em relação a metodologias didáticas e pedagógicas construindo assim um melhor percurso profissional".

Dessa forma, com base nos trabalhos mencionados, as atividades desplugadas têm se mostrada uma abordagem instigante, de maneira que, vem despertando nos discentes o interesse pelos conceitos computacionais, bem como a motivação em ingressar na área da Ciência da Computação. Além disto, os resultados obtidos com a utilização da abordagem desplugada têm cumprido com os objetivos que são estipulados, e tem tornado o processo de ensino e aprendizagem mais lúdico e eficiente.

\subsection{Construtivismo de Piaget}

Segundo Becker (1992), o Construtivismo não é uma metodologia de ensino. Todavia, "as teorias desenvolvidas a partir dos estudos na área da Psicologia influenciam a construção das teorias pedagógicas relacionadas ao processo de ensino e aprendizagem na escola" [Niemann e Brandoli, 2012, p. 4]. Em vista disso, a teoria de Piaget influenciou o movimento Construtivista.

$\mathrm{Na}$ abordagem Construtivista o discente constrói seu conhecimento junto com o professor, mas o aluno torna-se figura principal desse processo. Assim sendo, nesse processo de ensino e aprendizagem, o discente aprende por meio da assimilação, acomodação e equilibração. Para De Pádua (2009) na assimilação o aluno absorve informações do objeto que ele está se relacionando, ou seja, ele incorpora elementos externos. Segundo Becker (1992) ainda sobre a assimilação, os objetos que são assimilados resistem aos instrumentos de assimilação usados pelo discente, por isso, 0 aluno reage recriando esses instrumentos de assimilação, tornando-os mais poderosos. 
VIII Congresso Brasileiro de Informática na Educação (CBIE 2019)

Anais do XXV Workshop de Informática na Escola (WIE 2019)

$\mathrm{Na}$ acomodação, as estruturas mentais são metamorfoseadas para acomodar o objeto, e essa reestruturação busca o equilíbrio, portanto, essa busca pelo equilíbrio é definida por Piaget como equilibração [De Pádua 2009]. Logo, entende-se que o Construtivismo desperta influências no processo de ensino e aprendizagem, pois se o conhecimento é construído na relação do ser com o objeto a didática adotada pelo professor deve promover os meios para isso, e o que vem acontecendo no ensino de Redes é o contrário, Cantú et al. (2005) relatou que o docente está assumindo o papel de transmissor de informações e o aprendente de receptor, ou seja, nesse processo não acontece diálogo, e para haver aprendizado é necessário "diálogo - interações consigo mesmo ou com os outros" [Jonassen, 2008, p. 71].

\section{Metodologia}

A metodologia de pesquisa científica do presente trabalho constitui-se dos seguintes tipos de classificações de pesquisas: natureza, procedimentos técnicos e forma de abordagem do problema, indagadas por Prodanov e De Freitas (2013).

A natureza da pesquisa do presente trabalho é aplicada, de maneira que, possibilite gerar novos conhecimentos práticos de experiências com práticas desplugadas em Redes de Computadores. Sobre os procedimentos técnicos, essa é uma pesquisa participante, pois houve "interação entre pesquisadores e membros das situações investigadas" (Prodanov e De Freitas, 2013, p. 67]. Sobre a abordagem do problema, este trabalho apropria-se da forma qualitativa, de jeito que, "um fenômeno pode ser melhor compreendido no contexto em que ocorre e do qual é parte, devendo ser analisado numa perspectiva integrada" [Godoy, 1995, p. 21]. De acordo com Godoy (1995) os estudos qualitativos buscam compreender os fenômenos a partir da visão dos investigados, e essa forma de pesquisar expõe o dinamismo das situações, que muitas vezes são invisíveis para os observadores externos.

A presente pesquisa constituiu-se das seguintes etapas metodológicas: exploração, desenvolvimento de objetos desplugados, aplicação e análise. A seguir apresenta-se um detalhamento de como esses passos foram realizados.

Na exploração, realizou-se uma imersão no universo da Computação Desplugada, descobrindo a base pedagógica que sustenta essa metodologia, bem como seus objetivos em promover um processo de ensino e aprendizagem de conceitos computacionais de forma lúdica e significativa. Com relação a imersão, ocorreu por meio de pesquisas em artigos, teses, monografias, livros e vídeos. O critério para selecionar os trabalhos foram seus resumos, esses deviam relatar experiências com a utilização da abordagem desplugada. Referente ao desenvolvimento dos objetos desplugados, após conhecer o livro elaborado pelos idealizadores da Computação Desplugada e inteirar-se por outras iniciativas desplugadas ao redor do mundo percebeu-se como as práticas desplugadas são elaboradas.

Dessa forma, com base na ementa de um curso Técnico em Informática, mais especificamente, no componente de Redes de Computadores I, os objetos de aprendizagem desplugados foram elaborados. O quadro 1 ilustra quais conceitos de Redes de Computadores são contemplados pelos objetos desplugados elaborados. 
VIII Congresso Brasileiro de Informática na Educação (CBIE 2019)

Anais do XXV Workshop de Informática na Escola (WIE 2019)

\begin{tabular}{|l|l|}
\hline Objeto Desplugado & Conteúdo abordado \\
\hline $\begin{array}{l}\text { Conhecendo os dispositivos de } \\
\text { redes }\end{array}$ & $\begin{array}{l}\text { Funções básicas de dispositivos } \\
\text { usados em Redes de } \\
\text { Computadores }\end{array}$ \\
\hline Tabulosi & Conceitos básicos do Modelo OSI. \\
\hline
\end{tabular}

Quadro 1. Conteúdos abordados pelos objetos desplugados desenvolvidos.

Falando sobre a confecção dos objetos desenvolvidos, o Tabulosi foi elaborado utilizando uma cartolina, cola, cartas de baralhos, notas adesivas e também papéis A4. Nestes foram inseridos quadrados com números na parte superior direita e a descrição de ações que devem ser feitas durante o jogo na parte central. Seguidamente, foram recortados e colados na cartolina em ordem crescente. Para personalizar as cartas, foram colados na parte traseira notas adesivas e na parte frontal foi feito uma descrição sobre características do Modelo OSI (Open System Interconnection). Para construir o objeto (Conhecendo os dispositivos de rede), cartas de baralhos, piloto e cola foram utilizados.

Nas cartas, foram coladas na parte frontal a imagem de um dispositivo de rede obtido no Google Imagens, na traseira foram coladas notas adesivas, em seguida, enumeradas.

No âmbito da aplicação e análise, a aplicação ocorreu no turno matutino, com duração de 2 aulas de 50 minutos, com participação de 13 alunos. Dentro de sala de aula, foi feito uma breve apresentação dos objetos desplugados, depois o objeto desplugado (Conhecendo os dispositivos de redes) foi aplicado da seguinte maneira, o material foi colocado em uma mesa utilizada em geral pelo professor, em seguida, os discentes fizeram um círculo em volta dela, e assim começaram a interagir com o objeto desplugado. Em seguida, o Tabulosi foi executado, o jogo foi colocado em cima de algumas cadeiras e os discentes ficaram sentados nelas, circulando o tabuleiro, e logo começaram a interação.

Momentos antes de interagirem com os objetos desplugados, os discentes responderam dois questionários com o intuito de diagnosticar o que os discentes sabiam sobre Modelo OSI e dispositivos básicos utilizados em Redes de Computadores. Depois de interagir com os objetos, foi aplicado um outro questionário com o objetivo de saber o que os discentes pensaram sobre os objetos e seus sentimentos durante a interação com os mesmos. Esses dados foram analisados de forma interpretativa.

\section{Material desplugado elaborado}

O objeto desplugado (Conhecendo os dispositivos de redes) é um tipo de jogo da memória que tem como objetivo apresentar características básicas de dispositivos utilizados em Redes de Computadores. É composto por cartas divididas em dois tipos: cartas memórias e cartas conhecimentos, ilustradas na figura 1. Referente às primeiras (figura 1-a), são cartas que ilustram um dispositivo de rede na parte central, na parte inferior um número seguido pelo nome deste dispositivo. As cartas conhecimentos (figura 1-b), descrevem características de um dispositivo de rede, além disso, possuem um número na parte traseira, que coincide com o número da carta memória (figura 1-c). 
VIII Congresso Brasileiro de Informática na Educação (CBIE 2019)

Anais do XXV Workshop de Informática na Escola (WIE 2019)

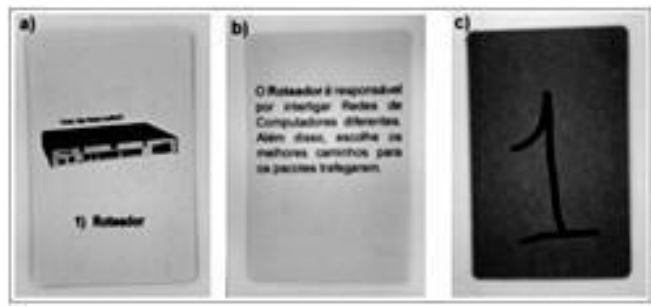

Figura 1. Cartas do objeto desplugado (Conhecendo os dispositivos de redes).

Com relação às regras do Conhecendo os dispositivos de redes, a ordem alfabética dos jogadores vai definir quem começa jogando. Ato contínuo, as cartas memórias e conhecimentos devem ser separadas. As cartas conhecimentos devem ser agrupadas de acordo com seu número da parte traseira, ou seja, cartas que possuem números iguais ficam juntas, conforme ilustra a figura 2 .

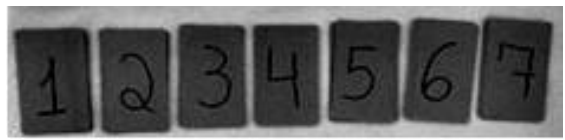

Figura 2. Disposição que as cartas conhecimentos devem ficar no objeto desplugado (Conhecendo os dispositivos de redes).

Finalizado o processo acima, devem ser embaralhadas somente as cartas memórias, e colocadas com a parte frontal para baixo. Os jogadores devem formar pares de cartas memórias iguais. Em seguida, o jogador deve ler uma carta conhecimento com o número correspondente com a carta memória que ele fez o par. Vence quem formar mais pares.

O Tabulosi é objeto desplugado que tem como objetivo introduzir conceitos referentes às sete camadas do Modelo OSI. Desta maneira, espera-se que os discentes possam compreender as principais funções básicas de cada camada desse modelo de referência. Conforme ilustrado na figura 3, o Tabulosi é composto por um dado de seis faces (figura 3-a), seis peças identificadoras enumeradas de 1 a 6 (figura 3-b), um tabuleiro contendo 31 casas (figura 3-c), e 26 cartas que descrevem características básicas sobre o Modelo OSI (figura 3-d).

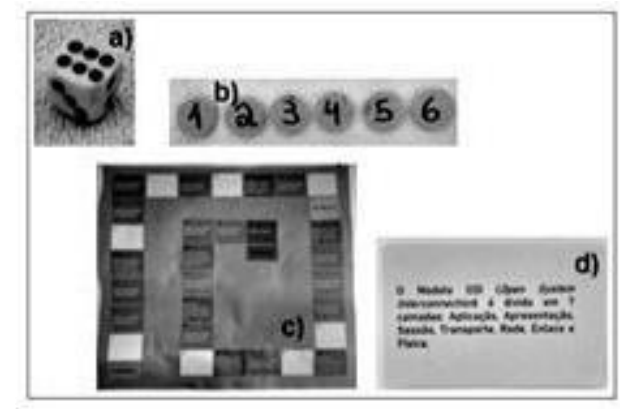

Figura 3. Peças do objeto desplugado (Tabulosi).

Sobre as regras do Tabulosi, os jogadores devem jogar o dado individualmente, e quem conseguir o número maior é o primeiro a começar jogando. Se os jogadores tirarem o mesmo número, o dado deve ser jogador novamente entre estes, até que aconteça o desempate. Depois disso, cada um deve escolher a sua tampa para se movimentar no tabuleiro. Com o processo acima finalizado, as tampas devem ser posicionadas na casa "LARGADA", e o primeiro jogador a começar a partida arremessa o dado e movimenta 
VIII Congresso Brasileiro de Informática na Educação (CBIE 2019)

Anais do XXV Workshop de Informática na Escola (WIE 2019)

sua tampa de acordo com o número que foi sorteado pelo dado. Então, chegando na casa sorteada o jogador deve observar o que está escrito, e fizer o que for solicitado. Vence o primeiro jogador a chegar na casa "CHEGADA".

\section{Resultados e discussões}

Antes da aplicação dos objetos desplugados, os discentes responderam dois questionários contendo 10 perguntas sobre conceitos básicos do Modelo OSI e sobre características de dispositivos utilizados em Redes de Computadores. As perguntas presentes no questionário foram classificadas como fácil, média e difícil. As fáceis valem 3 pontos, as médias 4 e difíceis 5. É possível fazer no máximo 37 pontos no questionário, mas tomouse como parâmetro a média de 25 pontos para considerar que os conceitos do Modelo OSI estão frescos na memória dos discentes, pois para obter essa pontuação os discentes teriam que acertar perguntas dos três níveis. Nesta perspectiva, obteve-se os seguintes resultados.

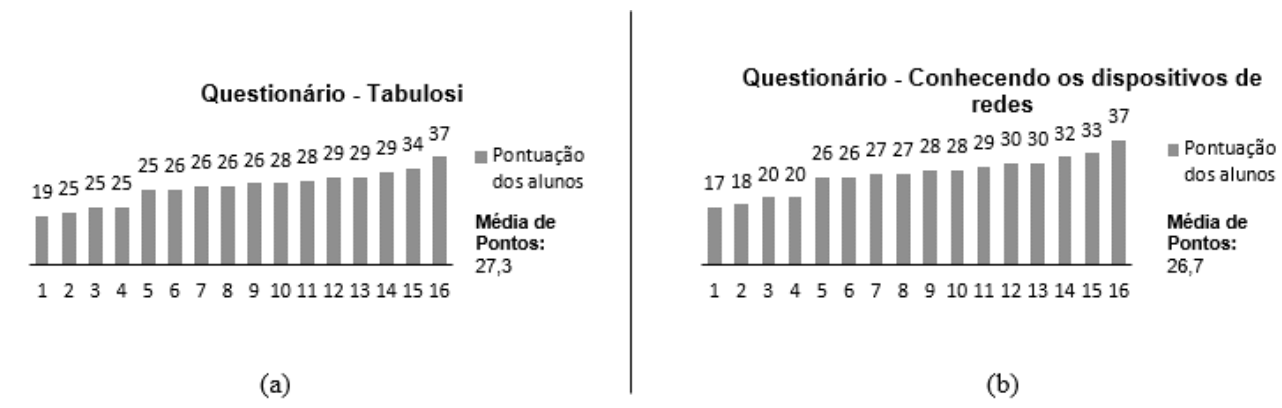

Figura 4. (a) está ilustrando a pontuação dos alunos no questionário sobre o Modelo OSI e (b) a pontuação no questionário sobre dispositivos de redes.

Conforme mostra a figura (4-a), os discentes obtiveram uma média de 27,3 pontos no questionário. Desta maneira, dos 16 alunos que responderam o questionário, 1 aluno fez 19 pontos, 4 alunos fizeram 25 pontos, 4 alunos fizeram 26 pontos, 2 alunos fizeram 28 pontos, 3 alunos fizeram 29 pontos, 1 aluno fez 34 pontos e outro 37. Portanto, de uma forma geral, com base nos resultados apresentados, percebe-se que os discentes têm consciência sobre os conceitos elementares referentes ao Modelo OSI.

Ilustrado na figura (4-b), os alunos alcançaram uma média de 26,7 pontos. Dos 16 alunos que responderam esse questionário, 1 aluno fez 17 pontos, 1 aluno fez 18 pontos, 2 alunos fizeram 20 pontos, 2 alunos fizeram 26 pontos, 2 alunos fizeram 27 pontos, 2 alunos fizeram 28 pontos, 1 aluno fez 29 pontos, 2 alunos fizeram 30 pontos, 1 aluno fez 32 pontos, 1 aluno fez 33 pontos e 1 aluno fez a pontuação máxima, 37 pontos. Assim, em um âmbito geral, os dados mostram que os discentes compreendem e conhecem as características básicas dos dispositivos comuns utilizados em Redes de Computadores.

Em relação a aplicação dos objetos desplugados, a pesquisa foi realizada no IFBA - Porto Seguro. A aplicação dos objetos ocorreu no turno matutino, com participação de 13 alunos, e teve duração de 2 aulas. Dentro da sala de aula, primeiramente as peças do (Conhecendo os dispositivos de redes) foram colocados em cima da mesa que o professor utiliza e de uma cadeira. Feito essa arrumação do jogo, foi feita uma explicação a respeito do funcionamento do objeto, explanando como fazer os pares, o que fazer depois desses pares estarem feitos, enfim, as regras do jogo. Depois do término da interação com o primeiro objeto, foi realizado a arrumação do Tabulosi, da seguinte forma, o tabuleiro foi colocado em cima de algumas cadeiras da sala de aula, e as cartas foram postas em cima 
VIII Congresso Brasileiro de Informática na Educação (CBIE 2019)

Anais do XXV Workshop de Informática na Escola (WIE 2019)

do tabuleiro, em seguida, os discentes formaram um círculo em torno do jogo, alguns alunos sentaram-se nas cadeiras para ficarem mais confortáveis. A figura 5, ilustra os discentes interagindo com os objetos desplugados.

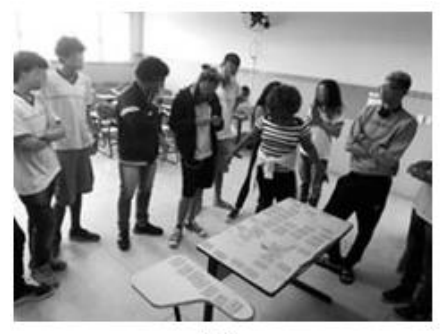

(a)

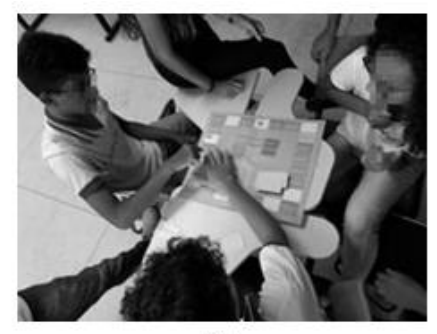

(b)

Figura 5. Foto ilustrando: (a) alunos interagindo com o objeto (Conhecendo os dispositivos de redes) e (b) alunos interagindo com o objeto (Tabulosi).

Por meio da observação, foi possível evidenciar que os discentes apresentaram pouca dificuldade em compreender a dinâmica dos objetos desplugados. Referente ao comportamento, eles demonstraram-se estar bem envolvidos com as atividades, em certos momentos foi possível perceber uma certa competitividade, o que estimulou alguns discentes a ficarem mais concentrados. Ainda sobre a interação, foi interessante observar que os discentes não demonstravam medo em errar ou em se expressar sobre um determinado assunto. Sobre possíveis dúvidas, os discentes não perguntaram nada relacionado ao conteúdo, mas em alguns momentos de leitura de cartas conhecimentos alguns alunos ouviam e diziam que não sabia sobre o conhecimento lido nas cartas, eles disseram "eu não sabia disso, você sabia? - Referindo-se para outro aluno". Neste contexto, observamos que o jogo abordou conceitos que o discente não sabia, com isso, reforça-se a ideia de que o objeto desplugado pode ajudar o discente a descobrir novos conhecimentos.

Após a interação com os objetos desplugados, foi aplicado um questionário com o objetivo de identificar o que os discentes sentiram durante a interação com os objetos desplugados, bem como seus pensamentos sobre o material desplugado apresentado. Com base nos resultados obtidos, os alunos se divertiram interagindo com o objeto desplugado (Conhecendo os dispositivos de redes), e esse divertimento é importante, de forma que, um ambiente de aprendizado deve ser alegre e despertar um prazer em aprender. Além disso, os dois objetos desplugados que foram aplicados despertaram nos discentes uma curiosidade sobre os conteúdos que eles abordam, como ilustra a figura 6 . Nesse cenário, esse despertar da curiosidade é fundamental, pois a curiosidade faz com que os alunos busquem mais conhecimento sobre aquele assunto.

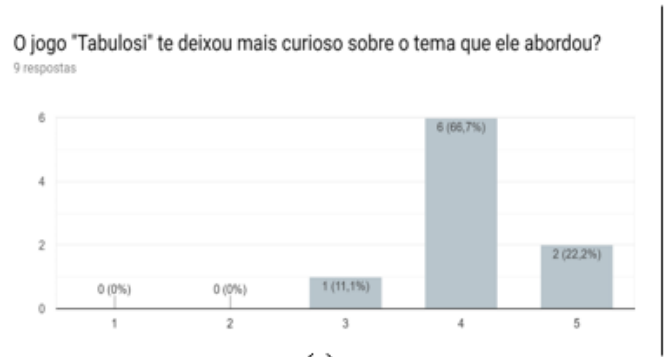

(a)

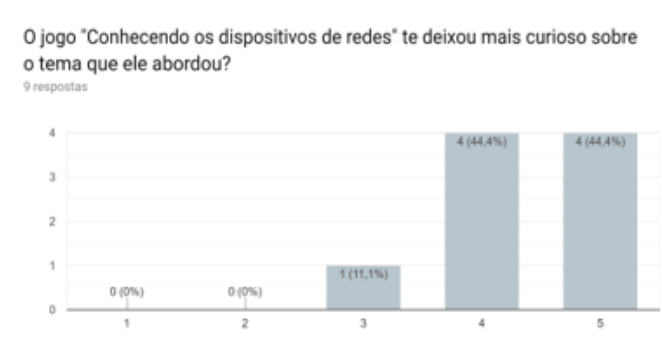

(b)

Figura 6. (a) está ilustrando o nível de curiosidade despertado pelo objeto desplugado (Tabulosi) e (b) ilustra o nível de curiosidade despertado pelo objeto desplugado (Conhecendo os dispositivos de redes). 
Os alunos gostaram da abordagem desplugada ser utilizada como estratégia para ensinar os conceitos de Redes de Computadores, além disto, também gostariam que os objetos desplugados aplicados fossem utilizados em suas aulas de Redes. Deste modo, os resultados obtidos neste questionário corroboram com as ideias presentes nesse trabalho, isto é, promover um processo de ensino e aprendizagem mais lúdico e significativo, assim como despertar nos discentes por meio da Computação Desplugada curiosidades sobre os temas que os objetos elaborados abordam.

\section{Considerações finais}

O presente trabalho teve como objetivo analisar o uso de objetos desplugados como estratégia para ensinar os conceitos de Redes de Computadores de forma lúdica e significativa. Para isto, foram construídos objetos desplugados que abordam diferentes conceitos da disciplina mencionada.

Os resultados mostraram que a interação dos discentes com os artefatos elaborados foram divertidas, e que os objetos despertaram neles uma curiosidade sobre os temas que eles abordam. Além disso, os objetos proporcionaram a possibilidade dos discentes reforçarem e lembrarem dos conhecimentos que eles já possuíam sobre os conceitos de Redes. Ainda mais, os alunos se identificaram com a abordagem desplugada, e gostariam que os objetos elaborados fossem utilizados nas aulas de Redes, essa vontade reforça o querer de aulas mais dinâmicas e prazerosas. Entende-se que após uma aula expositiva esses artefatos podem ser utilizados para reforçar o que foi dito de forma prática ou aplicar o material desplugado para introduzir um conteúdo de forma mais lúdica.

Do ponto de vista do investigador, envolver-se nessas interações despertou uma consciência de que o processo de ensino e aprendizagem deve ser mais divertido. Nesse divertimento, os laços são reforçados e erros podem ser cometidos sem medo de punições. O discente não tem medo em se expressar, de forma que, ele entende que o docente é parte daquela interação. Essa interação ainda permite que o docente entre no mundo linguístico dos alunos, podendo assim, dialogar de forma mais contextualizada.

Ainda da perspectiva do investigador, Piaget (1972) diz que o indivíduo aprende interagindo com o meio, passando por processos de assimilação, acomodação e equilibração. Em vista disso, foi possível observar o desequilíbrio que os objetos desplugados provocaram nos alunos, à primeira vista os discentes estavam com dificuldade em se relacionar com os objetos desplugados, mas com o passar do tempo eles foram assimilando e acomodando os objetos, assim, após algum tempo relacionandose com eles, pode-se notar um certo domínio por parte dos alunos dos conceitos que os objetos abordam.

\section{Referências}

Becker, Fernando. O que é construtivismo. Revista de educação AEC, Brasília, v. 21, n. 83, p. 7-15, 1992.

Bell, Tim et al. Ensinando Ciência da Computação sem o uso do computador. Computer Science Unplugged ORG, 2011.

Cantú, Evandro et al. Elementos para o fortalecimento da mediação docente na educação tecnológica: aplicação no ensino-aprendizagem de redes de computadores. 2005. 
VIII Congresso Brasileiro de Informática na Educação (CBIE 2019)

Anais do XXV Workshop de Informática na Escola (WIE 2019)

Cantú, Evandro; Farines, Jean Marie. Ensino-Aprendizagem de Redes de Computadores: Em Busca de uma Abordagem Metodológica Adaptada à Era da Internet. In: Anais do XXII Congresso da Sociedade Brasileira de Computação (SBC2002), Workshop de Ensino de Informática (WEI). 2002.

Cs Unplugged, How do I teach CS Unplugged?. 2019. Disponível em: https://csunplugged.org/en/how-do-i-teach-cs-unplugged/. Acessado em: 03 Jun. 2019.

De Pádua, Gelson Luiz Daldegan. A epistemologia genética de Jean Piaget. Revista FACEVV $\mid 1^{\circ}$ Semestre de, n. 2, p. 22-35, 2009.

Dohme, Vania D.'Angelo. Atividades lúdicas na educação: o caminho de tijolos amarelos do aprendizado. Vozes, 2003.

Ferreira, Ana Carolina et al. Experiência prática interdisciplinar do raciocínio computacional em atividades de Computação desplugada na educação básica. In: Anais do Workshop de Informática na Escola. 2015. p. 256.

Godoy, Arlida Schmidt. Introdução à pesquisa qualitativa e suas possibilidades. Revista de administração de empresas, v. 35, n. 2, p. 57-63, 1995.

Gonçalves, Dimas Antônio Silveira et al. Relato de experiência de alunos do curso de Licenciatura em Computação do IFMG-campus Ouro Branco na utilização de objetos de aprendizagem desplugados e do Scratch como instrumentos no ensino de programação. In: Anais dos Workshops do Congresso Brasileiro de Informática na Educação. 2013.

Jonassen, David. O uso das novas tecnologias na educação a distância e a aprendizagem construtivista. Em Aberto, v. 16, n. 70, 2008.

Niemann, Flávia de Andrade; Brandoli, Fernanda. Jean Piaget: um aporte teórico para o construtivismo e suas contribuições para o processo de ensino e aprendizagem da Língua Portuguesa e da Matemática. IX ANPED SUL Seminário de Pesquisa em Educação da Região Sul, 2012.

Piaget, Jean. Desenvolvimento e aprendizagem. Studying teaching, 1972.

Prodanov, Cleber Cristiano; De freitas, Ernani Cesar. Metodologia do trabalho científico: métodos e técnicas da pesquisa e do trabalho acadêmico- $2^{\mathrm{a}}$ Edição. Editora Feevale, 2013 .

Vieira, Anacilia; Passos, Odette; Barreto, Raimundo. Um relato de experiência do uso da técnica Computação desplugada. Anais do XXI WEI, p. 670-679, 2013. 